Cite this: RSC Advances, 2013, 3, 9949

Received 4th February 2013, Accepted 16th April 2013

DOI: 10.1039/c3ra41499j

www.rsc.org/advances

\title{
A tri(potassium sulfonate) derivative of perchlorotriphenylmethyl radical (PTM) as a stable water soluble radical-scavenger of the hydroxyl radical more powerful than 5,5-dimethyl-1-pyrroline- $\mathrm{N}$-oxide $\dagger$
}

\author{
Juan Antonio Mesa, Sergei Chávez, Lluís Fajarí, Josep Lluís Torres and Luis Juliá*
}

The tripotassium salt of tris(2,3,5,6-tetrachloro-4-hydroxysulfonylphenyl)methyl radical (3 $\mathrm{K}^{+} \mathrm{TSPTM}^{3-}$ ) reacts in water with hydroxyl radical very fast with a rate constant $\left(k=2.4 \times 10^{11} \mathrm{M}^{-1} \mathrm{~s}^{-1}\right)$ much higher than that of the reaction of hydroxyl radical with the spin trap 5,5-dimethyl-1-pyrroline- $N$-oxide (DMPO) ( $k$ $=3.4 \times 10^{9} \mathrm{M}^{-1} \mathrm{~s}^{-1}$ ). The reaction affects the radical character of the molecule and is monitored by electron paramagnetic resonance (EPR). The hydroxyl radical scavenging is established by the characterization of the resulting water-soluble product as the dipotassium salt of 4 -[bis(2,3,5,6tetrachloro-4-hydroxysulfonylphenyl)methylene]-2,3,5,6-tetrachlorocyclohexa-2,5-dien-1-one (2).

\section{Introduction}

Among all reactive oxygen species, the hydroxyl radical ( $\left.\mathrm{HO}^{\circ}\right)$ is by far the most reactive and therefore the most dangerous oxygen metabolite, and elimination of this radical is one of the major aims of antioxidant administration. ${ }^{1-5}$ One of the main methods used for the identification of hydroxyl radicals is the spin trapping. ${ }^{6}$ The spin trap is a compound which reacts rapidly with short-lived free radicals, such as hydroxyl radical, to yield more stable radical adducts that can be observed at room temperature by electron paramagnetic resonance (EPR) spectroscopy. The hyperfine splitting of the adduct radical provides information to identify the original radical. ${ }^{7}$ Other methods to identify the hydroxyl radical are based on reactions with known scavengers and identification of the products formed. ${ }^{8-10}$ These methods are similar to the method of spin trapping, but the identification of the final products differ, as they are not usually paramagnetic and, therefore, they have to be identified by other techniques. Finally, there are methods based on fluorescent probes. ${ }^{11-15}$ These methods monitor the appearance or disappearance of fluorescence after reaction with the hydroxyl radical.

We have been engaged for a time in the study of stable organic free radicals as chemical sensors of the antioxidant

Departament de Química Biològica i Modelització Molecular, Institut de Química Avançada de Catalunya (IQAC-CSIC), Jordi Girona 18-26, 08034 Barcelona, Spain. E-mail: ljbmoh@cid.csic.es

$\dagger$ Electronic supplementary information (ESI) available: HRMS-ESI spectrum of 4-methoxy-derived radical 4, and infrared, ${ }^{13} \mathrm{C}$ NMR, UV-vis and HRMS-ESI spectra of quinonemethide 2 . All this material is available free of charge via the Internet at RSC's electronic supplementary information (ESI) service. See DOI: 10.1039/c3ra41499j power of polyphenols. In this context, tris(2,4,6-trichloro-3,5dinitrophenyl)methyl radical (HNTTM) and tris(2,3,5,6-tetrachloro-4-nitrophenyl)methyl radical (TNPTM), radicals of the triphenylmethyl series (Scheme 1), have shown to be sensitive to electron transfer reactions with polyphenols. ${ }^{16-25}$ While HNTTM oxidizes catechol, pyrogallol and those polyphenols with cathecolic or pyrogallolic moieties, TNPTM is able to discriminate between pyrogallol and catechol, being only active with pyrogallol. More recently, we have reported the tris(2,3,5,6-tetrachloro-4-hydroxysulfonylphenyl)methyl radical (TSPTM), a stable and water-soluble radical, and studied the TSPTM-scavenging capacity of catechol, pyrogallol and ascorbic acid, in acidic aqueous solutions. ${ }^{26}$ TSPTM is a completely stable radical against hydrogen donors, unlike most of the free radicals, but is very sensitive to electron donors in electron transfer processes. Very recently, we have reported that the trication salt of this radical, $3 \mathrm{~K}^{+} \mathrm{TSPTM}^{3-}$, is able to discriminate between catecholic and pyrogallolic moieties of polyphenols in water solutions by taking measurements at

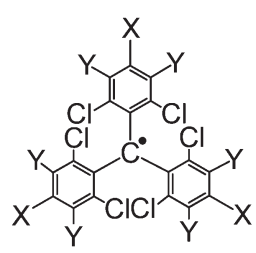

HNTTM: $X=\mathrm{Cl} ; Y=\mathrm{NO}_{2}$ TNPTM: $\mathrm{X}=\mathrm{NO}_{2} ; \mathrm{Y}=\mathrm{Cl}$

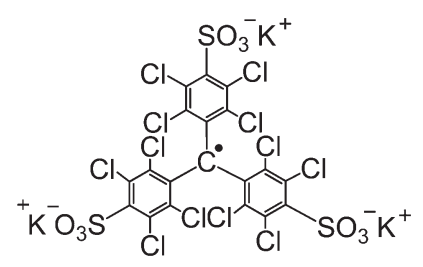

$3 \mathrm{~K}^{+} \mathrm{TSPTM}^{3-}$ 


$$
\mathrm{Fe}^{2+}+\mathrm{H}_{2} \mathrm{O}_{2} \longrightarrow \mathrm{Fe}^{3+}+\mathrm{HO}^{-}+\mathrm{HO}^{\circ}
$$

Scheme 2

different $\mathrm{pH}$ values. ${ }^{27}$ Now we want to highlight its remarkable effectiveness as a probe for the detection of hydroxyl radicals in water.

\section{Results and discussion}

To study quantitatively the reaction of TSPTM ${ }^{3-}$ and hydroxyl radical, we have used the Fenton reaction to generate the transient radical (Scheme 2). ${ }^{28}$ The reaction of TSPTM $^{3-}$ and hydrogen peroxide $(3 \%)$ in the presence of $\mathrm{FeSO}_{4}$ as catalyst in degassed (Ar) aqueous solution gave 4-[bis(2,3,5,6-tetrachloro4-hydroxysulfonylphenyl)methylene]-2,3,5,6-tetrachlorocyclohexa2,5-dien-1-one (2) with good yield (56\%) (Scheme 3). The reaction was monitored by the colour change from red, typical of the TSPTM $^{3-}$, to yellow. In fact, this quinonemethide 2 shows a characteristic UV-vis absorption $(\lambda=410 \mathrm{~nm})$, and it was also characterized by NMR and mass spectrometry.

The formation of quinonemethide 2 is consistent with the antiradical mechanism outlined in Scheme 3. Radical addition of hydroxyl to the aromatic ring, para to the central radical carbon atom in $\mathbf{1}$, to give the intermediate $\mathbf{3}$ (Scheme 3), seems to be the predominant reaction pathway; under similar conditions and in the presence of DMPO as spin trap instead of TSPTM $^{3-}$, the radical adduct DMPO-OH was obtained. Then, a rearrangement of the complex intermediate with desulfonation may be involved, most probably leading to a triarylmethyl anion with the release of $\mathrm{SO}_{3}$, which should be rapidly oxidized in a two-electron pathway to give the quinonemethide 2 ; no other modes of reaction seem to

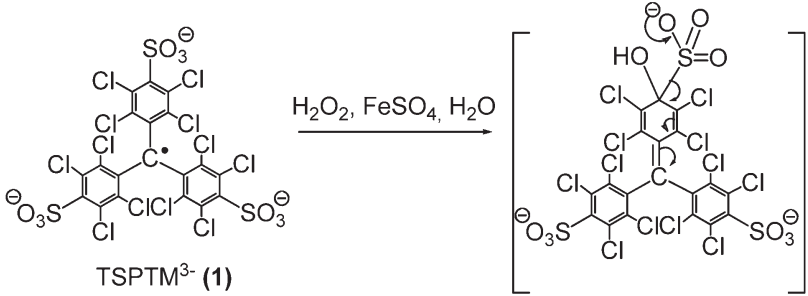

(3)

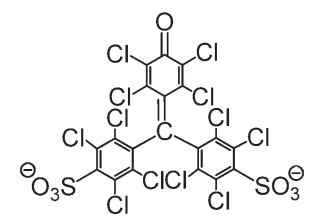

(2)

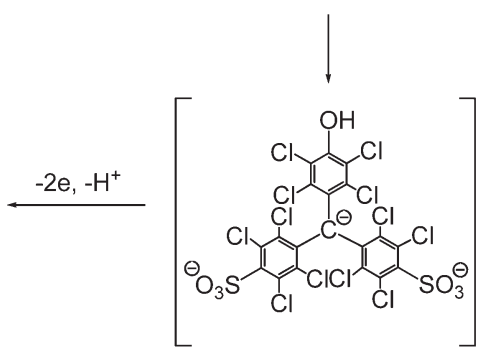

Scheme 3

$$
\mathrm{Fe}^{2+}+\mathrm{H}_{2} \mathrm{O}_{2} \longrightarrow\left[\left[\mathrm{Fe}^{I I I} \mathrm{OH}\right]^{2+} \cdot \mathrm{HO} \cdot \longrightarrow\left[\mathrm{Fe}^{\mathrm{IV}}\right]^{2+}+\mathrm{H}_{2} \mathrm{O}\right.
$$

$$
\begin{gathered}
{\left[\mathrm{Fe}^{\mathrm{IV} O}\right]^{2+}+\mathrm{CH}_{3} \mathrm{OH} \longrightarrow\left[\mathrm{Fe}^{\text {III }}(\mathrm{OH})\right]^{2+}+\mathrm{CH}_{3} \mathrm{O}^{\bullet}} \\
{\left[\mathrm{Fe}^{\prime \prime \prime}(\mathrm{OH})\right]^{2+}+\mathrm{CH}_{3} \mathrm{OH} \longrightarrow\left[\mathrm{Fe}^{\prime \prime}\left(\mathrm{H}_{2} \mathrm{O}\right)\right]^{2+}+\mathrm{CH}_{3} \mathrm{O}^{\bullet}}
\end{gathered}
$$<smiles>CO[C@H]1CCC(C)(C)N1[O]</smiles>

Scheme 4

compete with this process to any significant extent. The addition of the hydroxyl radical to the central radical carbon atom is discarded because the steric shielding of six orthochlorine atoms prevents the hydroxyl approach to the central carbon. Furthermore, the addition of the hydroxyl radical to the sulphur of the sulfonic group should be almost negligible, because once a hydroxyl radical reacts with a carbon bearing the sulfonic group, the other two sulfonic groups in the molecule remain unchanged. Furthermore, $\mathrm{H}_{2} \mathrm{O}_{2}$ was unable to oxidize TSPTM ${ }^{3-}$ in the same conditions, and TSPTM $^{3-}$ was not reduced by $\mathrm{FeSO}_{4}$ salt.

When the reaction between $\mathrm{H}_{2} \mathrm{O}_{2}$ and $\mathrm{Fe}(\mathrm{II})$ (molar ratio, 10-20 : 1) in the presence of DMPO was carried out in $\mathrm{MeOH}$ instead of $\mathrm{H}_{2} \mathrm{O}, \mathrm{DMPO}-\mathrm{OCH}_{3}$ was the only radical adduct detected by EPR. Under these conditions, methoxy $\left(\mathrm{CH}_{3} \mathrm{O}^{\circ}\right)$ radical and no hydroxyl $\left(\mathrm{HO}^{\circ}\right)$ radical is generated in the process. Assuming a radical mediated mechanism (Scheme 2), the hydroxyl radical abstracts a hydrogen atom from methanol to yield a hydroxymethyl $\left({ }^{\circ} \mathrm{CH}_{2} \mathrm{OH}\right)$ radical which then, in turn, reacts with DMPO to yield the radical adduct DMPO$\mathrm{CH}_{2} \mathrm{OH}^{29,30}$ As this adduct was not detected in the EPR, we assume that a non-radical mechanism predominates in the Fenton reaction under these conditions, ${ }^{31-38}$ and we suggest the reactions in Scheme 4 to explain the presence of the radical adduct DMPO-OCH 3 . Thus, the reaction between $\mathrm{H}_{2} \mathrm{O}_{2}$ and $\mathrm{Fe}(\mathrm{II})$ produces the oxidizing Fe(IV) species. Then, two $\mathrm{H}$ atoms are transferred consecutively from methanol molecules to reduce again to $\mathrm{Fe}(\mathrm{II})$ with the generation of methoxy radicals which, in the presence of DMPO, yield DMPO-OCH $\mathrm{CH}_{3}$.

When DMPO is substituted by TSPTM $^{3-}$ as radical scavenger, the stable methoxy-derived radical $\mathbf{4}$ is generated, characterized by mass spectrometry (HRMS-ESI (-) calcd for $\left[\mathrm{C}_{20} \mathrm{H}_{3} \mathrm{Cl}_{12} \mathrm{O}_{7} \mathrm{~S}_{2}\right] 2-422.2754$, found $m / z$ 422.2761) (Fig. S1, ESI $\dagger$ ). This stable radical is oxidized slowly (overnight) (controlled by EPR) to quinonemethide 2 , identified by mass spectrometry (Scheme 5).

Similar works have appeared in the literature regarding the degradation of stable polysubstituted triarylmethyl radicals against superoxide $\mathrm{O}_{2} \cdot-$ species. $^{39-41}$ The formation of 
<smiles>O=S(=O)([O-])C1(Cl)C(Cl)=C(Cl)C(=[Te])C1Cl</smiles>

\section{$\mathrm{H}_{2} \mathrm{O}_{2}, \mathrm{FeSO}_{4}$ $\mathrm{MeOH}$}

(1)<smiles>O=C1C(Cl)C(=C([Al])Br)C(Cl)C1Cl</smiles>

\section{$[\mathrm{Ox}]$}

(2)

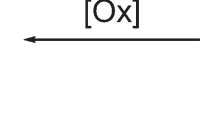

(1)
[<smiles>COC1(OC)C(Cl)(Cl)C(Br)=C(Br)C1(O)S(=O)(=O)O</smiles>

[Ox]<smiles>CC1(C)CCC(CCC2=[N+]([O-])C(C)(C)CC2)N1O</smiles>

TSPTM $^{3-}+\mathrm{HO}^{\circ} \longrightarrow 2$

Scheme 6

and TSPTM $^{3-}$ were present in the reaction medium (Scheme 6, reactions 1 and 2). The EPR spectrum of a water solution of TSPTM $^{3-}$ shows a single line centered at $g=2.0023$ with a line width, $\Delta H_{\mathrm{pp}}=1.1 \mathrm{G}$, and the EPR of a water solution of the spin adduct DMPO-OH ${ }^{47}$ shows a multiplet band centered at $g$ $=2.0055, \Delta H_{\mathrm{pp}}=1.4 \mathrm{G}$, consisting of a quartet with relative intensities: $1: 2: 2: 1$ and coupling constant values, $a_{\mathrm{N}}=a_{\mathrm{H}}=$ $14.8 \mathrm{G}$; a modulation amplitude of $1.86 \mathrm{G}$ is used in both experiments. A combination of both spectra is shown in Fig. 1.

Obviously, when both radical scavenging species compete with each other in the presence of hydroxyl radicals, the intensity of the signals of the spin adduct DMPO-OH and of TSPTM $^{3-}$ in the spectrum decrease with regard to the signals when both species operate individually, according to the corresponding reaction rates with hydroxyl radicals.

A quantitative analysis of the EPR spectra in the competitive method was performed recording the spectra 5 min after the addition of the last solution, the Fe(II) solution, into the reaction mixture of $\mathrm{H}_{2} \mathrm{O}_{2}$, DMPO and TSPTM ${ }^{3-}$. The concentration of both radicals, the DMPO-OH produced in the reaction and the remaining $\mathrm{TSPTM}^{3-}$ after reacting with hydroxyl radical, was finally proportional to the value of double integration of the EPR spectra. As the second lowest field line in the spectra of DMPO-OH is well separated from the singlet of TSPTM ${ }^{3-}$ (Fig. 1), the concentration of DMPO$\mathrm{OH}$ adducts in each spectrum was proportional to the doubleintegration value of this line multiplied by a factor of $6 / 2$ because of the $1: 2: 2: 1$ quartet displayed by this radical adduct. The concentration of $\mathrm{TSPTM}^{3-}$ was proportional to

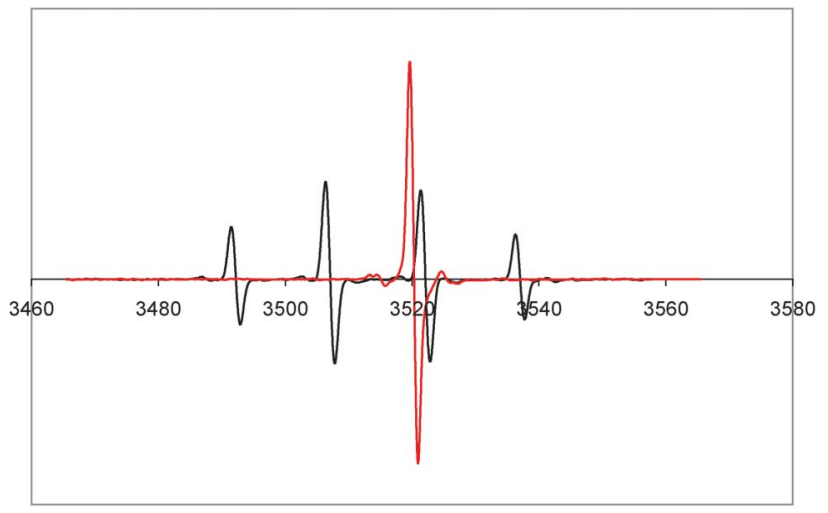

Fig. 1 EPR spectra of the spin adduct, DMPO-OH (black, a quartet, $1: 2: 2: 1$ ), and TSPTM $^{3-}$ (red, a singlet), both in water solution at room temperature. 


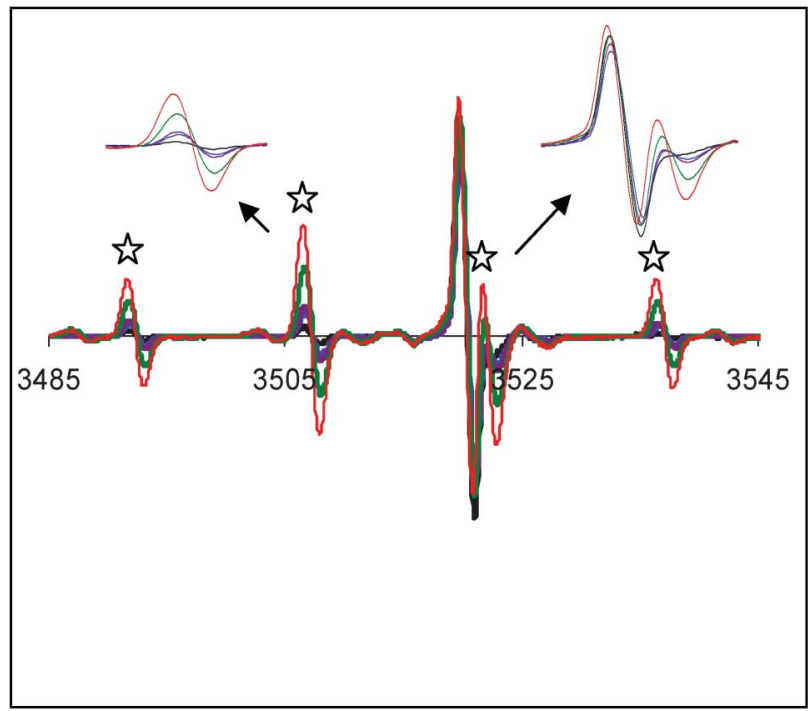

Fig. 2 EPR spectra of the radical adduct DMPO-OH (a quartet marked with stars) and TSPTM $^{3-}$ (a single band) in competitive radical-scavenging reactions of hydroxyl radicals generated in water solution from $\mathrm{H}_{2} \mathrm{O}_{2}(1.7 \mathrm{mM})$ and $\mathrm{FeSO}_{4}$ $\left(3.3 \times 10^{-2} \mathrm{mM}\right)$ in the presence of TSPTM ${ }^{3-}\left(6.7 \times 10^{-3} \mathrm{mM}\right)$ as spin sensor and varying amounts of DMPO (black, $3.15 \mathrm{mM}$; blue, $6.3 \mathrm{mM}$; purple, $9.45 \mathrm{mM}$; green, $12.6 \mathrm{mM}$; red, $18.9 \mathrm{mM}$ ) at the reaction time, $t=5 \mathrm{~min}$. Spectral conditions: modulation amplitude, $1.86 \mathrm{G}$; modulation frequency, $100 \mathrm{kHz}$; sweep width, $100 \mathrm{G}$; sweep time, $3.5 \mathrm{~min}$; time constant, $40.96 \mathrm{msec}$; microwave power, $30.3 \mathrm{~mW}$; receiver gain, $3.56 \times 10^{4}$. Inserted, details of the central part of the spectrum.

the value calculated by subtracting from the double-integration value of the combination of its line and the third lowest field line of DMPO-OH radical, the double-integration value of the second line which is obviously equal to the third line of the quartet. The concentration of TSPTM ${ }^{3-}$ reacted with hydroxyl radical will be the value of the initial concentration less the final concentration.

Fig. 2 shows the EPR spectra of the mixture of radicals, DMPO-OH and TSPTM $^{3-}$, of the solutions with a fixed concentration of $\mathrm{TSPTM}^{3-}$ and variable concentrations of DMPO within the first 5 min of reaction: Fig. 3 shows the EPR spectra of the mixture of radicals, DMPO-OH and TSPTM $^{3-}$, of the solutions with a fixed concentration of DMPO and variable concentrations of TSPTM $^{3-}$ within the first 5 min of reaction.

The reaction scheme for the complete process is determined by reactions (1) and (2) in Scheme 6. Assuming that both reactions are of second order, the rate of each reaction is given by eqn (1) and (2):

$$
\frac{d[\mathrm{DMPO}-\mathrm{OH}]}{d t}=k_{1}[\mathrm{DMPO}]\left[\mathrm{HO}^{\bullet}\right]
$$

and

$$
\frac{-d\left[\mathrm{TSPTM}^{3-}\right]}{d t}=k_{2}\left[\mathrm{TSPTM}^{3-}\right]\left[\mathrm{HO}^{\bullet}\right]
$$

Where $k_{1}$ and $k_{2}$ are the second-order rate constants for the reaction of hydroxyl radicals with DMPO and $\mathrm{TSPTM}^{3-}$,

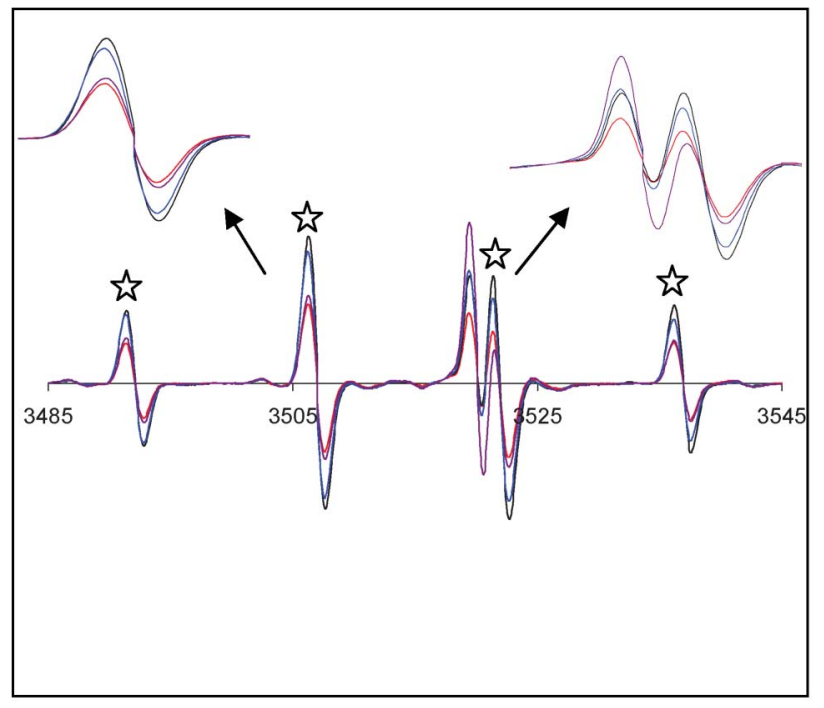

Fig. 3 EPR spectra of the radical adduct DMPO-OH (a quartet marked with stars) and $\operatorname{TSPTM}^{3-}$ (a single band) in competitive radical-scavenging reactions of hydroxyl radicals generated in water solution from $\mathrm{H}_{2} \mathrm{O}_{2}(1.7 \mathrm{mM})$ and $\mathrm{FeSO}_{4}$ $\left(3.3 \times 10^{-2} \mathrm{mM}\right)$ in the presence of DMPO $(1.27 \mathrm{mM})$ as spin trap and varying amounts of TSPTM $^{3-}$ (black, $6.6 \mu \mathrm{M}$; blue, $8.3 \mu \mathrm{M}$; purple, $9.9 \mu \mathrm{M}$; red, $13.2 \mu \mathrm{M}$ ) at the reaction time, $t=5 \mathrm{~min}$. Spectral conditions: modulation amplitude, 1.86 $\mathrm{G}$; modulation frequency, $100 \mathrm{kHz}$; sweep width, $100 \mathrm{G}$; sweep time, $3.5 \mathrm{~min}$; time constant, $40.96 \mathrm{msec}$; microwave power, $30.3 \mathrm{~mW}$; receiver gain, $3.56 \times$ $10^{4}$. Inserted, details of the central part of the spectrum.

respectively. Thus, the ratio of the second order rates of formation of DMPO-OH and disappearance of $\mathrm{TSPTM}^{3-}$ can be expressed as eqn (3):

$$
-\frac{d[\mathrm{DMPO}-\mathrm{OH}]}{d\left[\mathrm{TSPTM}^{3-}\right]}=\frac{k_{1}}{k_{2}} \frac{[\mathrm{DMPO}]_{0}}{\left[\mathrm{TSPTM}^{3-}\right]_{0}}
$$

Where $[\mathrm{DMPO}]_{0}$ and $\left[\mathrm{TSPTM}^{3-}\right]_{0}$ are the initial concentrations of the spin trap and the TSPTM ${ }^{3-}$, respectively. Thus, $k_{1} /$ $k_{2}$ can be calculated as the slope of the straight line when the ratio of the spin adduct formation and the decrease of the TSPTM $^{3-}$ concentration is plotted against the ratio of the initial concentrations of the spin trap and TSPTM $^{3-}$. Assuming the value $k_{1}=3.4 \times 10^{9} \mathrm{M}^{-1} \mathrm{~s}^{-1(44,45)}$ for the trapping reaction with DMPO, it is easy to calculate an approximate value for $k_{2}$. Fig. 4 and 5 show the linear regression of the competition kinetic data for these reactions taken by experiments at fixed concentrations of TSPTM $^{3-}$ and DMPO, respectively.

From Fig. 4, the ratio of $k_{1} / k_{2}$ determined was 0.010 . Assuming that $k_{1}=3.4 \times 10^{9} \mathrm{M}^{-1} \mathrm{~s}^{-1}$, the rate constant for the reaction of $\mathrm{HO}^{-}$with $\mathrm{TSPTM}^{3-}$ was $k_{2}=3.4 \times 10^{11} \mathrm{M}^{-1} \mathrm{~s}^{-1}$. From Fig. 5 , the ratio of $k_{2} / k_{1}$ determined was 44.67. Assuming that $k_{1}=3.4 \times 10^{9} \mathrm{M}^{-1} \mathrm{~s}^{-1}$, the rate constant for the reaction of $\mathrm{HO}^{\circ}$ with $\mathrm{TSPTM}^{3-}$ was $k_{2}=1.36 \times 10^{11} \mathrm{M}^{-1} \mathrm{~s}^{-1}$. The values of $k_{2}$ are the same order of magnitude and consistent with each other. The extremely high value of the rate constant, approximately 100 times greater than the rate constant value 


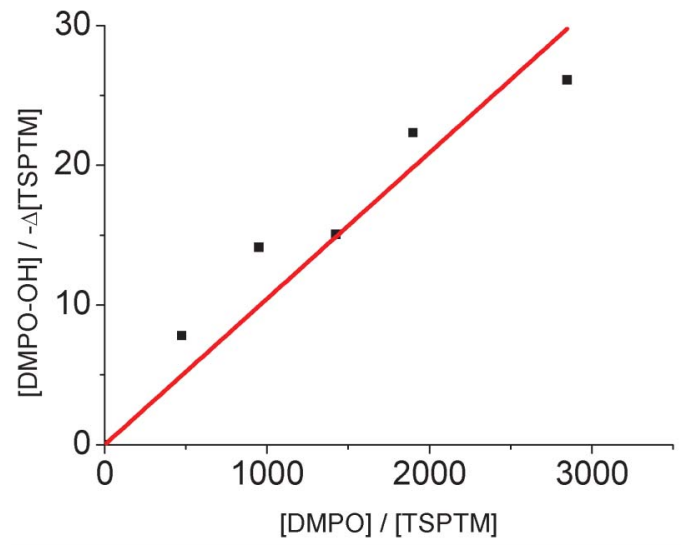

Fig. 4 Inhibition of the radical adduct of hydroxyl with DMPO as spin trap by TSPTM $^{3-}$. The hydroxyl radical was produced by the Fenton reaction from a water solution of $\mathrm{H}_{2} \mathrm{O}_{2}(1.7 \mathrm{mM})$ and $\mathrm{FeSO}_{4}\left(3.3 \times 10^{-2} \mathrm{mM}\right)$ containing TSPTM $^{3-}\left(6.7 \times 10^{-3} \mathrm{mM}\right)$ and in the presence of varying amounts of DMPO $(3.15,6.30,9.45,12.60$ and $18.90 \cdot \mathrm{mM})$. Linear regression as a lineal function $y=$ $0.010 x$, with a correlation coefficient of 0.97 .

of the hydroxyl-scavenging reaction with DMPO, is consistent with the high reactivity of hydroxyl radical with most organic compounds, whose reaction rates fall within the range of $10^{8}$ $10^{10} \mathrm{M}^{-1} \mathrm{~s}^{-1},{ }^{48}$ and indicates the extremely high scavenging ability of TSPTM $^{3-}$ towards hydroxyl radicals. So, very low concentrations of TSPTM $^{3-}(\sim 6-13 \mu \mathrm{M})$ competed successfully with high concentrations of DMPO as spin trap $(\sim 3-19$ $\mathrm{mM}$ ) in these competitive experiments. It appears that the electronic structure of the two open valence shell reagents, $\mathrm{HO}^{\circ}$ and $\mathrm{TSPTM}^{3-}$, and the fact that the molecule of TSPTM $^{3-}$ has three sites for hydroxyl radical attack, may be definitive factors in the high value of the rate constant.

One factor affecting these competing reactions is the stability of the radical adduct DMPO-OH. The decay of the DMPO-OH produced under the same conditions as in the competition reaction between the spin trap DMPO and TSPTM $^{3-}$, is shown in Fig. 6 as the smooth decrease of the intensity of the second spectral band in the EPR spectrum of DMPO-OH with time. The decay is assumed to be predominantly of first order kinetics due to the very low concentration of DMPO-OH $;^{44,45}$ the concentration value obtained by double integration of the spectral band after $3 \mathrm{~min}$ of reaction is approximately $13 \mu \mathrm{M}$. Furthermore, the concentration of $\mathrm{H}_{2} \mathrm{O}_{2}$ which is an oxidant that may additionally affect the decay rate of the radical adduct, is also very low.

Then, assuming a reaction of first order kinetics (eqn (4) and (5)),

$$
\begin{gathered}
-\frac{d[A]}{d t}=k[A] \\
\ln [A]=-k t+\ln \left[A_{0}\right]
\end{gathered}
$$

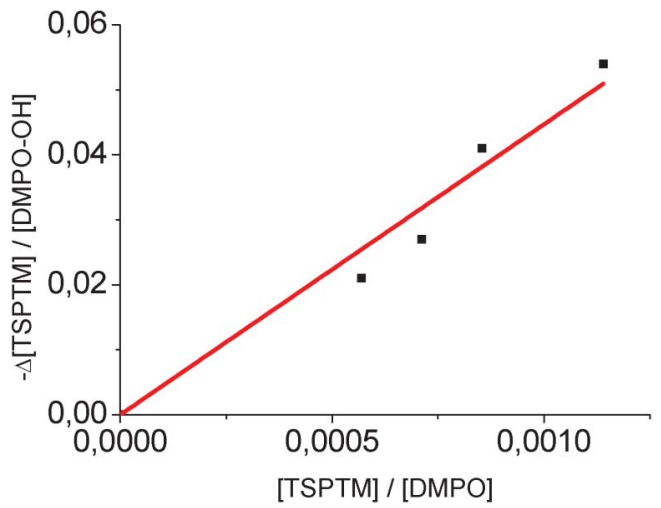

Fig. 5 Inhibition of the radical adduct of hydroxyl with DMPO as spin trap by TSPTM $^{3-}$. The hydroxyl radical was produced by the Fenton reaction from a water solution of $\mathrm{H}_{2} \mathrm{O}_{2}(1.7 \mathrm{mM})$ and $\mathrm{FeSO}_{4}\left(3.3 \times 10^{-2} \mathrm{mM}\right)$ containing DMPO $(12.7 \mathrm{mM})$ and in the presence of varying amounts of $\operatorname{TSPTM}^{3-}(6.6,8.3,9.9$, $13.2 \cdot \mu \mathrm{M})$. Linear regression as a function $y=44.67 x$, with a correlation coefficient of 0.987 .

the rate constant that results applying eqn (5) corresponds to the slope of the linear function, $k=-2.6 \pm 0.1 \times 10^{-2} \mathrm{~s}^{-1}$ (Fig. S2, ESI $\dagger$ ).

The very low value of the rate constant obtained in the decomposition of the radical adduct DMPO-OH in relation to the high value of its formation confirms that its low decay does not appreciably affect the results obtained in the competitive reaction between the spin trap DMPO and $\mathrm{TSPTM}^{3-}$ at $5 \mathrm{~min}$ reaction.

The formation of the quinonemethide 2 in the course of the reaction of the trisulphonic radical 1 with hydroxyl radical $\mathrm{HO}^{*}$ has been observed by electronic spectroscopy. UV-vis spectra of the mixtures present in the reactions between $\mathbf{1}$ and the Fenton reagent in diluted water solutions at different concentrations of the Fe(II) salt are shown in Fig. 7. The $\mathrm{Fe}(\mathrm{II})$ salt solutions were added to the reaction mixture one minute before recording the spectra. The reactions were virtually instantaneous as the spectra were identical beyond

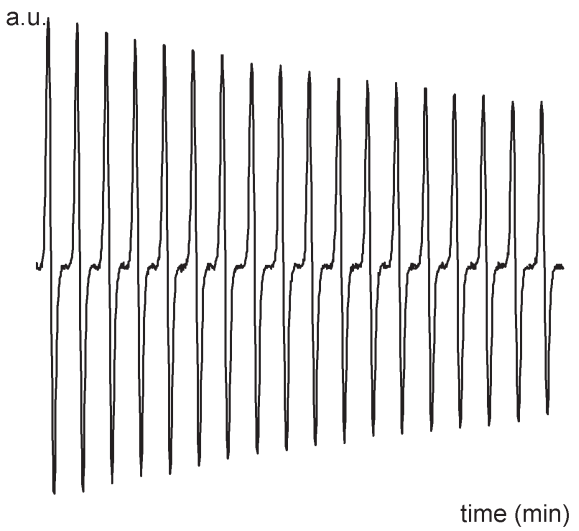

Fig. 6 Decay of the intensity of the second band of the EPR spectrum of the radical adduct DMPO-OH with time, from $3 \mathrm{~min}$ to $20 \mathrm{~min}$, each minute 


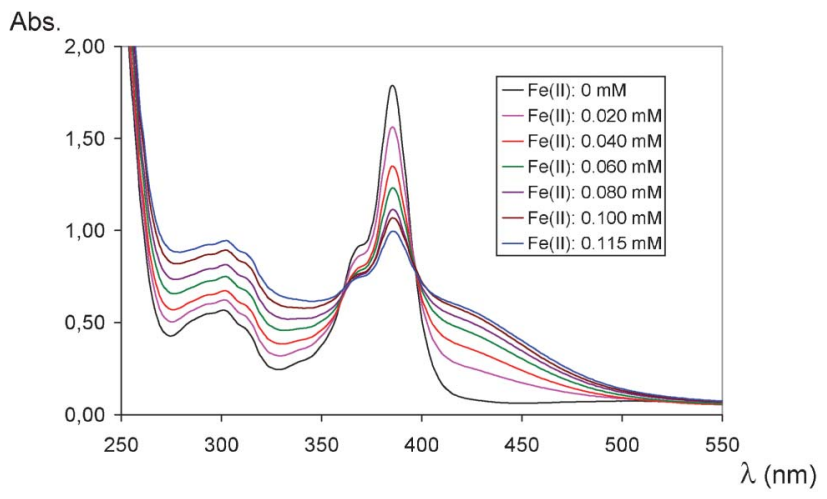

Fig. 7 UV-vis spectra of aqueous solutions of $\mathrm{H}_{2} \mathrm{O}_{2}$ (1.15 mM), $\mathrm{K}_{3}$ TSPTM (0.109 $\mathrm{mM}$ ) and different concentrations of $\mathrm{FeSO}_{4}$, as indicated in the legend. The spectra were recorded after one minute of adding the $\mathrm{FeSO}_{4}$ solutions.

this point. The decrease of the intensity of the band of the radical $1(\lambda=387 \mathrm{~nm})$ with $\mathrm{Fe}(\mathrm{II})$ concentration together with the simultaneous growth of the intensity of the broad and overlapped band of the quinonemethide $2(\lambda=410 \mathrm{~nm})$ are observed.

\section{Summary}

We introduce here a new HO${ }^{\bullet}$ scavenger, TSPTM $^{3-}$, that reacts with the hydroxyl radical very rapidly and whose rate constant is much higher $\left(k_{2}=2.4 \times 10^{11} \mathrm{M}^{-1} \mathrm{~s}^{-1}\right)$ than that of the reaction with DMPO. The source of hydroxyl radicals in these trials has been the Fenton reaction with hydrogen peroxide in the presence of iron(II) sulphate. Note that TSPTM $^{3-}$, under the same conditions, is stable-no variation is detected in the EPR signal-in the presence of hydrogen peroxide and is not reduced by iron(II) sulphate. TSPTM ${ }^{3-}$ is the first reported trityl radical reacting with hydroxyl radicals. Previous works with stable triarylmethyl radicals such as the tricarboxylic acid derivative of the perchlorotriphenylmethyl (PTM) series and other trityl radicals such as the tetrathiatriarylmethyl radicals showed that $\mathrm{HO}^{*}$ does not react significantly with them. ${ }^{39,49,50}$

The method of $\mathrm{HO}^{-}$-scavenging reaction with $\mathrm{TSPTM}^{3-}$ is similar to that of spin trapping with DMPO, but the identification of the reaction products is different. It is similar in that the scavenging of hydroxyl radicals is monitored by EPR, by examining the evolution of the signal showing the TSPTM $^{3-}$ spectrum. With the method of spin trap with DMPO, the identification of the $\mathrm{HO}^{\circ}$ radical is based on the appearance of a EPR signal corresponding to the radical adduct formed, whereas in the case of TSPTM ${ }^{3-}$, the initial EPR signal decreases as the adduct is being formed. The hydroxyl radical attacks one of the para phenyl carbon atoms of the molecule, generating a carbonyl group and the molecule losing its radical character. Therefore, due to the high reactivity of the hydroxyl radical and to its oxidizing character, TSPTM $^{3-}$ no longer reacts by electron transfer, as reported with polyphenols, ${ }^{26,27}$ but by substitution and oxidation to give rise to quinonemethide 2 .

One advantage of using TSPTM $^{3-}$ with respect of using DMPO is the increased sensitivity-study of the evolution of a single line of the TSPTM $^{3-}$ spectrum instead of the quartet of the DMPO-OH adduct and the increased rate constant of the reaction of the TSPTM $^{3-}$ with hydroxyl radical. A second advantage is the much greater stability of the $\mathrm{TSPTM}^{3-}$ as radical than the radical adduct DMPO-OH. The half-life of DMPO-OH depended on its initial concentration and varied from 15 to $60 \mathrm{~min}^{, 51,52}$ while TSPTM $^{3-}$ is completely stable for days. Finally, a third advantage is that TSPTM $^{3-}$ is much more water soluble than DMPO. All these properties make the new radical particularly useful for the determination of the oxidative status of biological tissues and fluids.

\section{Experimental section}

Hydrogen peroxide solution (3\%), iron(II)sulphate heptahydrate and 5,5-dimethyl-1-pyrroline $N$-oxide $(\geqslant 97 \%)$ were purchased from Aldrich and used without further purification, and $3 \mathrm{~K}^{+}$TSPTM $^{3-}$ was prepared as described. ${ }^{27}$

\section{EPR experiments}

The EPR spectra were recorded using a Bruker EMX-Plus 10/12 spectrometer, operating at the $\mathrm{X}$ band. Data acquisition and instrument control were achieved by using Bruker's WinEPR Acquisition software ( $\mathrm{V}$ 4.40), and data processing by using a Bruker Analytik GmbH (V 2.22). The water samples were examined in quartz capillary tubes inside a rectangular Bruker ER 4102ST cavity of the EPR instrument.

\section{Reaction of the tripotassium salt of $\operatorname{TSPTM}^{3-}\left(3 \mathrm{~K}^{+}\right.$TSPTM $\left.^{3-}\right)$ with Fenton reagent}

A solution of $3 \mathrm{~K}^{+} \mathrm{TSPTM}^{3-}(20 \mathrm{mg} ; 20 \mu \mathrm{mol})$ and an aqueous solution of $\mathrm{FeSO}_{4}(1 \mathrm{mM})(2.5 \mathrm{~mL} ; 2.5 \mu \mathrm{mols})$ in degassed $\mathrm{H}_{2} \mathrm{O}_{2}$ (3\%) (2.5 mL; 2.20 mmols) was stirred at rt (24 h). The solution was lyophilized and the precipitate with acetone and silica gel was introduced in a column chromatography and eluted with EtAcO-MeOH $(5: 2, \mathrm{v} / \mathrm{v})$ to give the dipotassium salt of 4-[bis(2,3,5,6-tetrachloro-4-hydroxysulphonylphenyl)methylene]-2,3,5,6-tetrachlorocyclohexadien-1-one (2) (9.2 mg; $56 \%$ ) as a yellow solid: IR (KBr, $\left.\mathrm{cm}^{1}\right)$ : 1657, 1310, 1223, 1132, 1065 (Fig. S3, ESI $\dagger$ ); ${ }^{13} \mathrm{C}$ NMR ( $\left.\mathrm{CD}_{3} \mathrm{OD}, 400 \mathrm{MHz}\right) \delta 170.7,147.8$, 146.6, 144.5, 144.8, 141.2, 140.2, 139.8, 137.4 (Fig. S4, ESI $\dagger$ ); UV-vis $\left(\mathrm{H}_{2} \mathrm{O}\right) \quad \lambda_{\max } ; \mathrm{nm} \quad\left(\varepsilon ; \mathrm{L} \mathrm{mol}^{-1} \mathrm{~cm}^{-1}\right)$ 300(6700), 410(11 600), 685(430) (Fig. S5, ESI $\dagger$ ); HRMS-ESI (-) calcd for $\left[\mathrm{C}_{19} \mathrm{Cl}_{12} \mathrm{O}_{7} \mathrm{~S}_{2}\right]^{\tilde{2}} 414.7636$, found $m / z 414.7657$ (Fig. S6, ESI $\dagger$ ).

\section{Preparation of samples for kinetics measurements}

a) $3 \mathrm{~K}^{+} \mathrm{TSPTM}^{3-}(99.64 \mu \mathrm{M})$ in water: $20 \mathrm{mg}$ of radical in $1 \mathrm{~mL}$ of water; then, $1 \mathrm{~mL}$ of this solution was diluted to $200 \mathrm{~mL}$. b) DMPO (37.8 mM) in water: $21.40 \mathrm{mg}$ of DMPO in $5 \mathrm{~mL}$ of water. c) $\mathrm{H}_{2} \mathrm{O}_{2}(9.9 \mathrm{mM})$ in water: $1.13 \mathrm{~mL}$ of $\mathrm{H}_{2} \mathrm{O}_{2}(3 \%)$ in 100 $\mathrm{mL}$ of water. d) $\mathrm{FeSO}_{4} \cdot 7 \mathrm{H}_{2} \mathrm{O}(1 \mathrm{mM})$ in water: $13.9 \mathrm{mg}$ of $\mathrm{FeSO}_{4} \cdot 7 \mathrm{H}_{2} \mathrm{O}$ in $50 \mathrm{~mL}$ of water. 


\section{Kinetics measurements for the competitive reaction}

The rate of reaction of hydroxyl radicals with TSPTM $^{3-}$ was determined by studying the kinetic competition between TSPTM $^{3-}$ and DMPO in the EPR spectrometer. The technique is quite simple: the appearance of an EPR spectrum corresponding to the radical adduct DMPO-OH (a quartet, $1: 2: 2: 1$ ) and the disappearance of a single signal corresponding to $\mathrm{TSPTM}^{3-}$ are simultaneously monitored at a fixed time of reaction ( $5 \mathrm{~min}$ ).

Solutions with a fixed concentration of TSPTM ${ }^{3-}: 50 \mu \mathrm{L}$ of $\mathrm{H}_{2} \mathrm{O}_{2}(9.9 \mathrm{mM}), 20 \mu \mathrm{L}$ of $3 \mathrm{~K}^{+}$TSPTM $^{3-}(99.64 \mu \mathrm{M})$, different volumes of DMPO $(37.8 \mathrm{mM})(25,50,75,100$ and $150 \mu \mathrm{L})$, and the corresponding volumes of water $(195,170,145,120$ and 70 $\mu \mathrm{L}$ ) until a final volume of the solutions of $300 \mu \mathrm{L}$. Finally, 10 $\mu \mathrm{L}$ of $\mathrm{FeSO}_{4} \cdot 7 \mathrm{H}_{2} \mathrm{O}(1 \mathrm{mM})$ were added to start the reactions.

Solutions with a fixed concentration of DMPO: $50 \mu \mathrm{L}$ of $\mathrm{H}_{2} \mathrm{O}_{2}(9.9 \mathrm{mM}), 100 \mu \mathrm{L}$ of DMPO $(37.8 \mathrm{mM})$, different volumes of $3 \mathrm{~K}^{+} \mathrm{TSPTM}^{3-}(99.64 \mu \mathrm{M})(20,25,30$ and $40 \mu \mathrm{L})$, and the corresponding volumes of water $(120,115,110,100 \mu \mathrm{L})$ until a final volume of the solutions of $300 \mu \mathrm{L}$. Finally $10 \mu \mathrm{L}$ of $\mathrm{FeSO}_{4} \cdot 7 \mathrm{H}_{2} \mathrm{O}(1 \mathrm{mM})$ were added to start the reactions.

\section{Stability of the DMPO-OH}

1) Preparation of the sample. Solution: $200 \mu \mathrm{L}$ of $\mathrm{H}_{2} \mathrm{O}_{2}(10.0$ $\mathrm{mM}), 600 \mu \mathrm{L}$ of DMPO ( $42.4 \mathrm{mM}), 360 \mu \mathrm{L}$ of $\mathrm{H}_{2} \mathrm{O}$, and $40 \mu \mathrm{L}$ of $\mathrm{FeSO}_{4} \cdot 7 \mathrm{H}_{2} \mathrm{O}(1 \mathrm{mM})$. 2) Kinetics measurements. The stability of the radical adduct DMPO-OH was determined by recording the second band of the spectral multiplet in the EPR spectrometer every minute from 3 to $20 \mathrm{~min}$. The obtained values of the intensity of the band multiplied by 3 considering the spectrum multiplicity and converted in concentration values by a standard aqueous solution of $3 \mathrm{~K}^{+} \mathrm{TSPTM}^{3-}(6.5 \mu \mathrm{M})$, are processed according to a first order kinetics.

\section{Acknowledgements}

Financial support for this research from the Spanish Ministry of Science and Innovation through projects AGL2009-12374C03-03/ALI and CTQ2009-13797 is gratefully acknowledged. J.A.M. gratefully acknowledges the Spanish Foreign Office Department for a pre-doctoral grant (AECI). We also thank the EPR service of the Institute for Advanced Chemistry of Catalonia-CSIC (Spain) for recording the EPR spectra and the scientific-technical services of the University of Barcelona for recording the mass spectra.

\section{Notes and references}

1 A. Gosslau and L. Z. Reusing, Z. Gerontol. Geriatr., 2002, 35, 139-150.

2 L. J. Marnett, Carcinogenesis, 2000, 21, 361-370.

3 S. S. Leonard, G. K. Harris and X. Shi, Free Radical Biol. Med., 2004, 37, 1921-1942.

4 F. Li, L. Ji, Y. Luo and K. Oh, Chemosphere, 2007, 67, 13-19.

5 K. Jomova and M. Valko, Toxicology, 2011, 283, 65-87.

6 G. R. Buettner, Free Radical Biol. Med., 1987, 3, 259-303.

7 E. G. Janzen, Methods Enzymol., 1984, 105, 188-198.
8 B. Halliwell and J. M. C. Gutteridge, FEBS Lett., 1981, 128, 347-351.

9 M. S. Backer and J. M. Gebicki, Arch. Biochem. Biophys., 1984, 234, 258-264.

10 J. Diguiseppi and I. Fridovich, Arch. Biochem. Biophys., 1980, 205, 323-329.

11 X. Qu, L. J. Kirschenbaum and E. T. Borish, Photochem. Photobiol., 2000, 71, 307-313.

12 G. M. Makrigiorgos, E. Bump, C. Huang, J. BaranowskaKortylewicz and A. I. Kassis, Free Radical Biol. Med., 1995, 18, 669-678.

13 K. Setsukinai, Y. Urano, K. Kakinumas, H. J. Majita and T. Nagano, J. Biol. Chem., 2003, 278, 3170-3175.

14 N. Soh, K. Makihara, E. Sakoda and T. Imato, Chem. Commun., 2004, 496-497.

15 G. Cui, Z. Ye, J. Chen, G. Wang and J. Yuan, Talanta, 2011, 84, 971-976.

16 J. L. Torres, B. Varela, E. Brillas and L. Juliá, Chem. Commun., 2003, 74-76.

17 A. Jiménez, A. Selga, J. L. Torres and L. Juliá, Org. Lett., 2004, 6, 4583-4586.

18 S. Touriño, A. Selga, A. Jiménez, L. Juliá, C. Lozano, D. Lizárraga, M. Cascante and J. L. Torres, J. Agric. Food Chem., 2005, 53, 4728-4735.

19 C. Lozano, J. L. Torres, L. Juliá, A. Jiménez, J. J. Centelles and M. Cascante, FEBS Lett., 2005, 579, 4219-4225.

20 C. Lozano, L. Juliá, A. Jiménez, S. Touriño, J. J. Centelles, M. Cascante and J. L. Torres, FEBS J., 2006, 273, 2475-2486.

21 A. Carreras, I. Esparbé, E. Brillas, J. Rius, J. L. Torres and L. Juliá, J. Org. Chem., 2009, 74, 2368-2373.

22 J. L. Torres, A. Carreras, A. Jiménez, E. Brillas, X. Torrelles, J. Rius and L. Juliá, J. Org. Chem., 2007, 72, 3750-3756.

23 S. Touriño, D. Lizárraga, A. Carreras, S. Lorenzo, V. Ugartondo, M. Mitjans, M. P. Vinardell, L. Juliá, M. Cascante and J. L. Torres, Chem. Res. Toxicol., 2008, 21, 696-704.

24 A. Carreras, M. L. Mateos-Martín, A. Velásquez-Palenzuela, E. Brillas, M. Cascante, L. Juliá and J. L. Torres, J. Agric. Food Chem., 2012, 60, 1659-1665.

25 J. Yang, G.-Y. Liu, D.-L. Lu, F. Dai, Y.-P. Qian, X.-L. Jin and B. Zhou, Chem.-Eur. J., 2010, 16, 12808-12813.

26 J. A. Mesa, A. Velázquez-Palenzuela, E. Brillas, J. L. Torres and L. Juliá, Tetrahedron, 2011, 67, 3119-3123.

27 J. A. Mesa, J. L. Torres and L. Juliá, Talanta, 2012, 101, 141-147.

28 S. Goldstein, D. Meyerstein and G. Czapski, Free Radical Biol. Med., 1993, 15, 435-445.

29 H. Iwahashi, C. E. Parker, R. P. Mason and K. B. Tomer, Rapid Commun. Mass Spectrom., 1990, 4, 352-354.

30 U. Jurva, H. V. Wikström and A. P. Bruins, Rapid Commun. Mass Spectrom., 2002, 16, 1934-1940.

31 J. D. Rush and W. H. Koppenol, J. Biol. Chem., 1986, 261, 6730-6733.

32 I. Yamazaki and L. H. Piette, J. Biol. Chem., 1990, 265, 13589-13594.

33 I. Yamazaki and L. H. Piette, J. Am. Chem. Soc., 1991, 113, 7588-7593.

34 L. A. Reinke, J. M. Rau and P. B. McCay, Free Radical Biol. Med., 1994, 16, 485-492.

35 M. L. Kremer, Int. J. Chem. Kinet., 2006, 38, 725-736. 
36 M. J. Louwerse, P. Vassilev and E. J. Baerends, J. Phys. Chem. A, 2008, 112, 1000-1012.

37 K. Barbusinski, Ecol. Chem. Engin., 2009, 16, 347-358.

38 H. Bataineh, O. Pestovsky and A. Bakac, Chem. Sci., 2012, 3, 1594-1599.

39 C. Decroos, Y. Li, G. Bertho, Y. Frapart, D. Mansuy and J. L. Boucher, Chem. Commun., 2009, 1416-1418.

40 C. Decroos, Y. Li, A. Soltani, Y. Frapart, D. Mansuy and J. L. Boucher, Arch. Biochem. Biophys., 2010, 502, 74-80.

41 Y. Liu, Y. Song, F. De Pascali, X. Liu, F. A. Villamena and J. L. Zweier, Free Radical Biol. Med., 2012, 53, 2081-2091.

42 M. Ballester, J. Riera, J. Castañer, A. Rodriguez, C. Rovira and J. Veciana, J. Org. Chem., 1982, 47, 4498-4505.

43 J. Carilla, L. Fajarí, L. Juliá, J. Riera and L. Viadel, Tetrahedron Lett., 1994, 35, 6529-6532.

44 E. Finkelstein, G. M. Rosen and E. J. Rauckman, J. Am. Chem. Soc., 1980, 102, 4994-4999.

45 P. R. Marriott, M. J. Perkins and D. Griller, Can. J. Chem., 1980, 58, 803-807.

46 E. Finkelstein, G. M. Rosen and E. J. Rauckman, Arch. Biochem. Biophys., 1980, 200, 1-16.

47 G. M. Pieper, C. C. Felix, B. Kalyanaraman, M. Turk and A. M. Roza, Free Radical Biol. Med., 1995, 19, 219-225.

48 There are many examples in the literature of the high reactivity of hydroxyl radical with organic compounds. To mention only some examples: the bisbenzylisoquinoline alkaloid cepharanthine with various biological effects, is a potent hydroxyl radical scavenger with an apparent rate constant of $1.39 \times 10^{10} \mathrm{M}^{-1} \mathrm{~s}^{-1}$ (K. Kogure, K. Tsuchiya, K. Abe, M. Akasu, T. Tamaki, K. Fukuzawa and H. Terada, Biochim. Biophys. Acta, Gen. Subj., 2003, 1622, 1-5. Ascorbic acid $\left(10^{10} \mathrm{M}^{-1} \mathrm{~s}^{-1}\right), \alpha$-tocopherol $\left(10^{10} \mathrm{M}^{-1} \mathrm{~s}^{-1}\right)$ and butylated hydroxytoluene $\left(6 \times 10^{9} \mathrm{M}^{-1} \mathrm{~s}^{-1}\right)$ good antioxidant agentys (M. G. Simic, Methods Enzymol., 1990, 186, 89-100), and Rebamipide, an amino acid derivative of $2(1 \mathrm{H})$-quinolinone with effective antiulcer properties $(2.42$ $\times 10^{10} \mathrm{M}^{-1} \mathrm{~s}^{-1}$ ) (Y. Naito, T. Yoshikawa, T. Tanigawa, K. Sakurai, K. Yamasaki, M. Uchida and M. Kondo, Free Radical Biol. Med., 1995, 18, 117-123) are also potent hydroxyl radical scavengers.

49 V. K. Kutala, F. A. Villamena, G. Ilangovan, D. Maspoch, N. Roques, J. Veciana, C. Rovira and P. Kuppusamy, J. Phys. Chem. B, 2008, 112, 158-167.

50 C. Rizzi, A. Samouilov, V. K. Kutala, N. L. Parinandi, J. L. Zweier and P. Kuppusamy, Free Radical Biol. Med., 2003, 35, 1608-1618.

51 P. Tsai, S. Pou, R. Straus and G. M. Rosen, J. Chem. Soc., Perkin Trans. 2, 1999, 1759-1764.

52 K. Nakamura, T. Kauno, H. Ikai, E. Sato, T. Mokudai, Y. Niwano, T. Ozawa and M. Cono, Bull. Chem. Soc. Jpn., 2010, 83, 1037-1046. 